\title{
Subject differences in exponents of psychophysical power functions for inferred, remembered, and perceived area
}

\author{
JOSÉ APARECIDO DA SILVA, SUZI LIPPI MARQUES, and ERASMO MIESSA RUIZ \\ University of São Paulo at Ribeirão Prêto, Ribeirão Prêto, Brazil
}

\begin{abstract}
Data are presented from two magnitude estimation experiments in which the geographical areas of Brazilian states were judged. In Experiment 1 observers estimated the areas of the states in three conditions: in the presence of a map (perceived area), using memory following study of a map (remembered area), and using only general knowledge of Brazilian geography (inferred area). The results showed that the psychophysical power law describes well the inferred, remembered, and perceived magnitude estimates of areas of states. As had been found previously for areas of states, the remembered exponent approximated the square of the perceived exponent. Experiment 2 examined the correlations of the power functions exponents for observers who estimated areas of states on two sessions separated by an interval of 1 month. As in Experiment 1, observers estimated the areas from inference, from memory following study of a map, or in the presence of a map. Again, comparison of remembered and perceived psychophysical functions showed that for both sessions the remembered exponent was equal to the square of the perceived exponent. Since the correlations between Sessions 1 and 2 were fairly high and positive, the results also showed that all modes of judgments manifest temporal stability for an interval of at least 1 month between sessions. Stable individual differences can be shown for the exponent of the psychophysical power function for magnitude estimates of inferred, remembered, and perceived area. Although the exponent varies from one individual to another, the power function accurately describes the data of all observers in all conditions.
\end{abstract}

Magnitude estimates of area generally have been described by a power function of the form $J=k A^{n}$, where $J$ is the apparent judgment, $A$ is the physical area, $k$ is a scaling factor, and $n$ is an exponent (Baird, 1970; M. Teghtsoonian, 1965). The exponent $n$ is generally considered the more important parameter, since it indicates the curvature of the function. For perceptual judgments of area, the exponent is near .75 when observers are asked to judge the apparent area. This finding is supported by a large number of experiments and by a variety of psychophysical scaling procedures involving both the numerical and nonnumerical assessment of the apparent area (for reviews, see Baird, 1970; Da Silva, Dos Santos, \& Da Silva, 1983).

Large individual differences in the exponent for apparent area (and for other sensory or perceptual attributes) have been observed by many authors (for reviews, see da Silva \& Fukusima, 1986; M. Teghtsoonian \& R. Teghtsoonian, 1983), so that different possible causes for the variability in individual exponents have been proposed

This research was supported by Grants 85/2135-9, 85/2199-7, and 85/1625-2 from Fundação de Amparo à Pesquisa do Estado de São Paulo (FAPESP), Brazil. The preparation of the manuscript was supported by Grant 30.0567-85 from Conselho Nacional de Desenvolvimento Científco e Tecnológico (CNPq). We thank Jack M. Loomis for his helpful comments on an earlier version of this article. Requests for reprints should be sent to J. A. Da Silva, Department of Psychology, University of São Paulo, 14049 Ribeirão Prêto, São Paulo, Brazil.
(Borg, 1986; R. Teghtsoonian \& M. Teghtsoonian, 1986). However, studies of the stability of psychophysical power function exponents produced by an individual over time have led to inconclusive results. On the one hand, for example, M. Teghtsoonian and R. Teghtsoonian $(1971,1983)$ used magnitude estimation to scale length and area in five sessions separated by $24-h$ periods and again after an intersession interval of 1 year. They found individual exponents for both continua to be relatively stable for $24 \mathrm{~h}$, but to lose stability beyond that interval. On the other hand, for example, Verrillo (1983), employing the method of absolute magnitude estimation, found a high temporal stability for two groups of observers who estimated line length in two sessions. One group was retested after 1 year and the other after 2 years. This temporal stability was observed in both the exponent values of the power function and in the numerical estimates themselves.

The primary concern of the present study was with the stability of individual exponents for judged area over a long intersession interval (1 month). The two experiments reported in this paper used conditions and instructions similar to those used by Kerst and Howard (1978). Experiment 1 was essentially a replication of their Experiments 1 and 2, in which the observers made inferred, remembered, and perceived estimates of geographical areas. The purpose was to extend the generality of previously reported differences in remembered and perceived exponents. In Experiment 2 the observers made similar 
judgments on two sessions separated by an interval of 1 month. The purpose was to determine the temporal stability of the power function exponents for psychophysical scaling of inferred, remembered, and perceived areas of states.

\section{EXPERIMENT 1}

\section{Method}

Observers. The observers, 60 students between 17 and 26 years of age, partially satisfied a course requirement by participating in the experiment.

Materials and Procedure. The observers recorded their area estimates of the 25 states of Brazil on a previously prepared 26-page booklet of response sheets. Sheet 1 contained written instructions. Following the instruction sheet, each sheet had the name of one state, and the sheets in each booklet were arranged in a different random order for each participant.

Each of 60 observers was randomly assigned to one of three groups. The first group of observers judged area of states from memory, using general knowledge of Brazilian geography (infer group-G1). The second group estimated the area of states from memory, after studying a copy of the map placed on their desks (remember group-G2). The third group made the estimates while viewing a copy of the map of the 25 states (perceive group-G3). An outline map $(21.6 \times 33 \mathrm{~cm})$ showing only the boundaries and names of the states was provided for all observers of the remember and perceive groups. Observers in the infer group received only the booklet of 26 response sheets with the instruction sheet. Observers in the remember group were handed copies of the map and then were given a brief instruction sheet that asked them to study the map for a 7-min period to get a good idea of the relative dimensions of the states. Immediately following this period of study, the experimenters collected the maps and distributed the booklet of response sheets with the instruction sheet. The observers in the perceive group received the booklet of response sheets, the instruction sheet, and a copy of the map all at the same time.

The method of magnitude estimation was used with the area of the state of São Paulo as a modular area. This standard was chosen because of its being in the middle of the rank order of the physical variable and because it was very familiar for all observers. The instructions to the observers emphasized that they could use any numbers appropriate for representing the apparent geographical area of each state. It was also explained that the area of São Paulo was to serve as a standard and that it should be assigned a value of 100 units. Each state was judged only once. The observers were tested in groups during a class period. No participant required more than 20 min to complete the task.

\section{Results and Discussion}

The psychophysical function. For each observer a straight line was fitted by the method of least squares, relating log magnitude estimates to log actual geographical area. The assigned modulus was treated as a judgment (equal to 100). The slope $(n)$, the scale factor, and the coefficients of determination $\left(r^{2}\right)$ were computed for each observer. The arithmetic mean exponents for each group of observers, the standard deviations, and coefficients of determination are presented in Table 1 . The mean exponents were: .40 (range .12-.91), .63 (range .22-1.01), and .79 (range .42-1.03) for G1, G2, and G3, respectively. The good quality of the fits for individual subjects is indicated by the mean coefficients of determination $\left(r^{2}\right)$ for the individual fitted lines: $.45, .73$, and .94 , respectively, for $G 1, G 2$, and G3. Because large differences were found between the coefficients of determination, we can say that
Table 1

Mean Exponents (n), Standard Deviations ( $S D)$, and Coefficients of Determination $\left(r^{2}\right)$ of Best-Fitting Power Functions for Inferred, Remembered, and Perceived Magnitude Estimates of Geographical Area

\begin{tabular}{lllll}
\hline \multicolumn{1}{c}{ Group } & $n$ & $S D$ & Range & $r^{2}$ \\
\hline Infer & .40 & .19 & $.12-.91$ & .454 \\
Remember & .63 & .21 & $.22-1.01$ & .733 \\
Perceive & .79 & .13 & $.42-1.03$ & .940 \\
\hline
\end{tabular}

the power function fits the judgments of perceived area much better than those for inferred and remembered areas.

The exponent obtained for the perceive group shows good agreement with those obtained for apparent area (between .60-.90) by M. Teghtsoonian (1965), by Baird, Green, and Luce (1980), and by da Silva and Macedo (1983), and analyzed by Baird (1970) and by da Silva et al. (1983). Furthermore, those obtained for the infer and remember groups fell within the range expected from earlier studies (Kerst \& Howard, 1978, 1984; Lundberg \& Ekman, 1972; Moyer, Bradley, Sorensen, Whiting, \& Mansfield, 1978; Osaka, 1983), in which similar attributes and experimental conditions were used.

An analysis of variance (ANOVA) of the individual exponents revealed that the differences between the mean exponents were significant $[F(2,57)=23.32, p<.001]$. Subsequent comparisons by Duncan's test $(p<.05)$ showed that the mean exponents observed for the infer and remember groups were smaller than that observed for the perceive group and that the mean exponent for the infer group was smaller than that for the remember group. In addition, the mean remember exponent was essentially equal to the square of the mean perceive exponent. This pattern of results is in good agreement with that obtained in previous studies and confirms the relationship between the perceive and remember exponents postulated by Kerst and Howard (1978), by Moyer et al. (1978), and by Moyer, Sklarew, and Whiting (1982). These researchers have hypothesized that two power functions with the same exponent intervene between the actual physical magnitude of an attribute and its remembered dimension estimate. The first function represents the perceptual stage and the second pertains to recall. In the perceptual task, only the first stage is involved, whereas both are involved in the task with remembered stimuli.

\section{EXPERIMENT 2}

The results of Experiment 1 showed that the perceived, remembered, and inferred estimates of geographical areas of states were related to actual stimulus magnitude by power functions and that the remembered exponent was approximately equal to the square of the perceived exponent. Experiment 2 used similar experimental conditions to determine the temporal stability of the individual psychophysical functions for inferred, remembered, and perceived estimates of the areas of states. Observers judged the areas of states in two sessions separated by 1 month. 


\section{Method}

Observers. The observers, 60 students between 17 and 26 years of age, were recruited from psychology courses; they received credit for their participation. The observers were assigned to the same conditions as in Experiment 1; thus, there were 20 observers in each group, G1, G2, and G3. Because some of the observers failed to appear for Session 2, the final $N$ s were 19 for G1, 17 for G2, and 18 for G3. None had participated in Experiment 1.

Materials and Procedure. The materials and the procedure employed were essentially the same as those used in Experiment 1. Also, instructions were identical to those of Experiment 1 . All observers made magnitude estimates of the areas of the 25 Brazilian states in two sessions separated by 1 month. The second session was a replication of the first session in that area was judged only once. Each observer had different random orders of the 25 response sheets in Sessions 1 and 2. Within each group the observers had different random orders. The observers did not know they would be tested a second time until that moment arose (in the classroom).

\section{Results and Discussion}

The psychophysical function. For each observer in Sessions 1 and 2, a least squares fit of $\log$ magnitude estimates as a function of log actual geographical areas was obtained. The slope $(n)$, the scale factor, and the coefficients of determination were computed for each observer. These values, together with the range of exponents, are presented in Table 2. The mean exponents for Session 1 were $.51, .60$, and .84 , and for Session 2 were $.49, .64$, and .81 , respectively, for G1, G2, and G3. A $3 \times 2$ (group $\times$ session, with repeated measures on last factor) ANOVA carried out on the individual exponents yielded a significant effect of group $[F(2,51)=17.15, p<.001]$, while showing that session was a nonsignificant source $(F<1)$. Furthermore, the interaction of group and session was nonsignificant $[F(2,51)=1.25, p=.294]$. As in Experiment 1 , the exponents presented in Table 2 for the two sessions fell within the range of exponents expected from earlier studies; they also confirm the claim of Kerst and Howard $(1978,1984)$ that the exponent obtained for remembered judgments is approximately equal to the square of the exponent obtained for perceived estimates of the same attribute. This pattern of results was found for magnitude estimates obtained in two sessions separated by one month.

Session-to-session correlations. Pearson correlation coefficients were calculated between the individual exponents obtained in Sessions 1 and 2 for each group. These correlations are presented in the last column of Table 2 . The correlations between the exponents obtained in Ses-

Table 2

Mean Exponents (n), Standard Deviations (SD), Coefficients of Determination $\left(r^{2}\right)$, and Session 1-Session 2 Correlations $\left(r_{12}\right)$ Between Power Function Exponents for Inferred, Remembered, and Perceived Magnitude Estimates of Geographical Area

\begin{tabular}{lllllllllll}
\hline & \multicolumn{4}{c}{ Session 1 } & & \multicolumn{3}{c}{ Session 12 } & \\
\cline { 2 - 4 } \cline { 7 - 8 } Groups & $n$ & $S D$ & Range & $r^{2}$ & & $n$ & $S D$ & Range & $r^{2}$ & $r_{12}$ \\
\hline Infer & .51 & .20 & $.19-.92$ & .51 & & .49 & .20 & $.13-1.05$ & .59 & $.63^{*}$ \\
Remember & .60 & .19 & $.26-.94$ & .71 & & .64 & .24 & $.28-1.08$ & .70 & $.80^{*}$ \\
Perceive & .84 & .12 & $.61-1.05$ & .95 & & .81 & .10 & $.58-.98$ & .95 & $.53^{*}$ \\
\hline
\end{tabular}

${ }^{*} p<.02$. sions 1 and 2 were $.63(p<.001)$ for the infer group, $.80(p<.001)$ for the remember group, and .53 $(p<.02)$ for the perceive group. All correlations were fairly high and positive. These correlations, together with the nonsignificant effect of session on the exponents, indicate that although observers differ in their exponents, the manipulation of repeating the estimates in two sessions separated by 1 month exerts no systematic effect on the mean value of the exponents for inferred, remembered, and perceived psychophysical functions. In short, the observers showed consistency in inferred, remembered, and perceived magnitude estimates of areas of states.

\section{GENERAL DISCUSSION}

The experiments described in this report show that the psychophysical power law describes well the inferred, remembered, and perceived estimates of the areas of states. Moreover, the size of the exponents for the inferred and remembered psychophysical functions were smaller than that obtained for the perceived psychophysical function. The following ordinal relationship between the sizes of the mean exponents was obtained: perceived $>$ remembered $>$ inferred. This relationship, as suggested by Mulholland, Da Silva, Janczura, and Penso (1981) and by Wiest and Bell (1985), may represent differences in the amount or complexity of cognitive processing required to produce an estimate. The experiments also confirm the hypothesis proposed by Kerst and Howard $(1978,1984)$ that the remembered estimates involve a second power transformation identical to the original perceived one, so that the remembered exponent is approximately equal to the square of the perceived exponent.

In addition, the results suggest that the psychophysical power law describes the individual performance as well as average group performance and that the individual inferred, remembered, and perceived exponents manifest a temporal stability of at least 1 month.

\section{REFERENCES}

BAIRD, J. C. (1970). Psychophysical analysis of visual space. New York: Pergamon Press.

Baird, J. C., Green, D. M., \& LuCE, R. D. (1980). Variability and sequential effects in cross-modality matching of area and loudness. Journal of Experimental Psychology: Human Perception \& Performance, 6, 277-289.

BORG, G. (1986). Interindividual and intermodal comparison of perceptual intensities. In B. Berglund, U. Berglund, \& R. Teghtsoonian (Eds.), Fechner Day 86 (pp. 123-128). Stockholm, Sweden: International Society for Psychophysics.

Da Silva, J. A., Dos Santos, R. A., \& Da Silva, C. B. (1983). Análise psicofísca do espaço visual- teoria e pesquisa: Tributo a $\mathbf{S}$. S. Stevens. Arquivos Brasileiros de Psicologia, 35, 3-53.

DA Silva, J. A., \& Fukusima, S. S. (1986). Stability of individual psychophysical functions for perceived distance in natural indoor and outdoor settings. Perceptual \& Motor Skills, 63, 891-902.

Da Silva, J. A., \& Macedo, L. (1983). Efeitos de algumas variáveis experimentais sobre a invariância das escalas perceptivas. Arquivos Brasileiros de Psicologia, 39, 48-70.

KeRST, S. M., \& HowARD, J. H., JR. (1978). Memory psychophysics for visual area and length. Memory \& Cognition, 6, 327-335.

Kerst, S. M., \& HowARD, J. H., JR. (1984). Magnitude estimates of perceived and remembered length and area. Bulletin of the Psychonomic Society, 22, 517-520.

LUNDBERG, V., \& EkMAN, G. (1972). Geographical data as psychophysical stimuli. Scandinavian Journal of Psychology, 13, 81-88.

Moyer, R. S., Bradley, D. R., Sorensen, M. H., Whiting, J. C., \& MANSFIELD, D. P. (1978). Psychophysical functions for perceived and remembered size. Science, 200, 330-332. 
Moyer, R. S., Sklarew, P., \& Whiting, J. (1982). Memory psychophysics. In H. G. Gussler \& P. Petzold (Eds.), Psychophysical judg ment and the process of perception (pp. 35-46). Berlin, West Germany: VEB Deutscher Verlag der Wissenschaften.

Mulholland, T. M., Da Silva, J. A., Janczura, G. A., \& Penso, M. A. (1981, October). Estimação de razão de distância em escala geográfica. Paper presented at the XIV Reunião Anual da Sociedade de Psicologia de Ribeirão Prêto, Ribeirão Prêto.

OsaKa, N. (1983). Memory psychophysics for perceived length and area: A psychophysical approach to memory processes. Faculty of Letter Review, 17, 15-28.

Teghtsoonian, M. (1965). The judgment of size. American Journal of Psychology, 78, 392-402.

Teghtsoonian, M., \& Teghtsoonian, R. (1971). How repeatable are Stevens' power law exponents for individual subjects? Perception \& Psychophysics, 10, 147-149.
Teghtsoonian, M., \& Teghtsoonian, R. (1983). Consistency of individual exponents in cross-modal matching. Perception \& Psychophysics, 33, 203-214.

Teghtsoonian, R., \& Teghtsoonian, M. (1986). Individual differences in the judgment of perceived magnitude. In B. Berglund, U. Berglund, \& R. Teghtsoonian (Eds.), Fechner Day 86 (pp. 129-134). Stockholm, Sweden: International Society for Psychophysics.

VerRILLo, R. T. (1983). Stability of line-length estimates using the method of absolute magnitude estimation. Perception \& Psychophysics, 33, 261-266.

WIEST, W. M., \& BeLL, B. (1985). Stevens' exponent for psychophysical scaling of perceived, remembered, and inferred distance. Psychological Bulletin, 98, 457-470.

(Manuscript received for publication January 6, 1987.) 